\title{
The price of growth in the medical-device industry
}

\section{Citation}

Garber, Alan M. 2006. The price of growth in the medical-device industry. New England Journal of Medicine 355, 4:337-339.

\section{Published Version}

10.1056/NEJMp068085

\section{Permanent link}

http://nrs.harvard.edu/urn-3:HUL.InstRepos:11501764

\section{Terms of Use}

This article was downloaded from Harvard University's DASH repository, and is made available under the terms and conditions applicable to Other Posted Material, as set forth at http:// nrs.harvard.edu/urn-3:HUL.InstRepos:dash.current.terms-of-use\#LAA

\section{Share Your Story}

The Harvard community has made this article openly available.

Please share how this access benefits you. Submit a story.

\section{Accessibility}



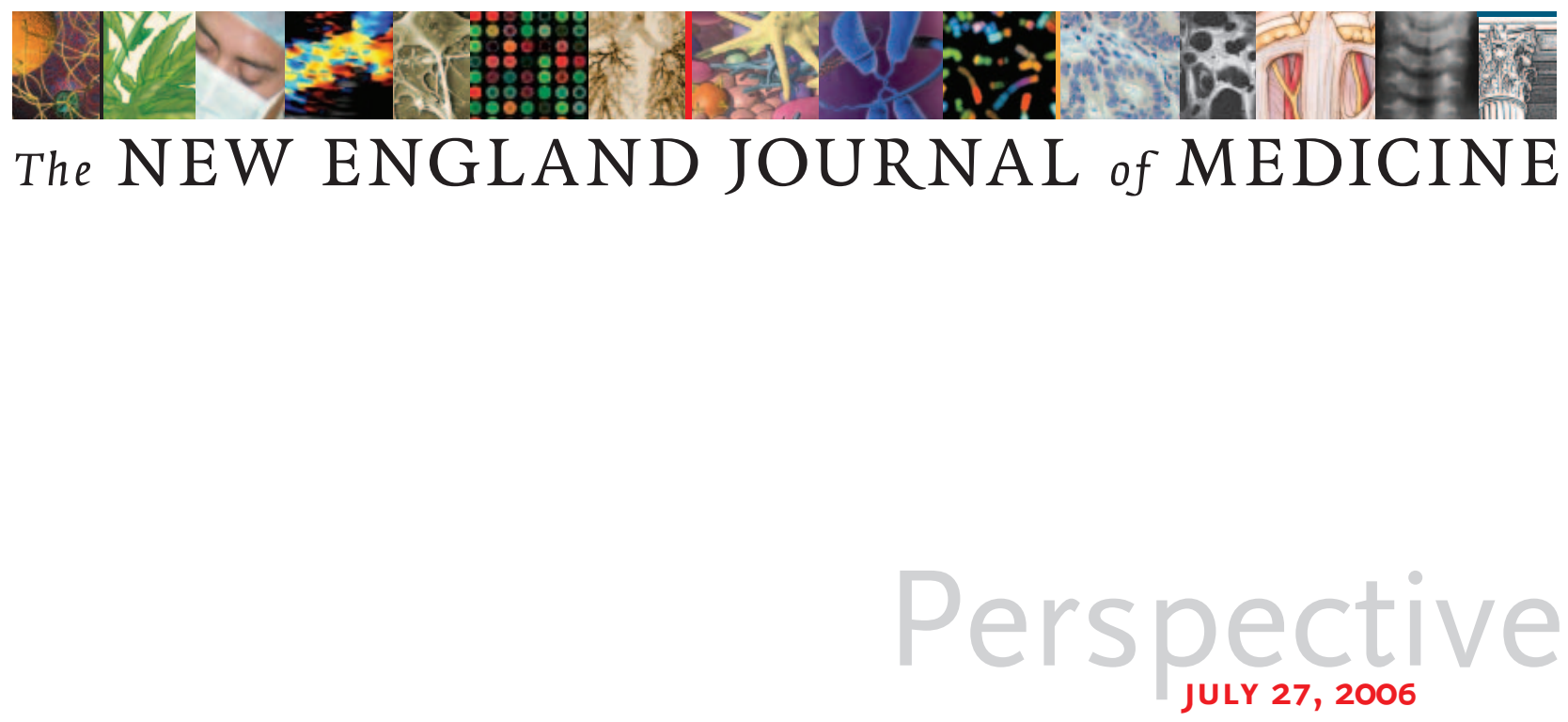

BUSINESS AND MEDICINE

\section{The Price of Growth in the Medical-Device Industry}

Alan M. Garber, M.D., Ph.D.

\section{Tn one of the most dramatic corporate acquisi- Itions in recent memory, Boston Scientific, a large manufacturer of medical devices, outbid industry giant Johnson \& Johnson to purchase Guidant}

Corporation earlier this year. Joining Boston Scientific in this effort was Abbott Laboratories, which paid $\$ 5$ billion for Guidant's endovascular-device business. The outcome could hardly have been anticipated when Johnson \& Johnson agreed to purchase Guidant for $\$ 25$ billion in December 2004. In the wake of disclosures of lawsuits over allegedly defective Guidant devices, Guidant agreed to reduce the purchase price to $\$ 21.5$ billion. Then Boston Scientific stepped in with a higher offer and won, in the end, with a bid valued at $\$ 27.5$ billion - substantially more than Boston Scientific's own market value of $\$ 20$ billion.

Winning a common-value auc- tion - in which the item should have the same worth to all the bidders - is seldom an unmixed triumph. According to economist Richard Thaler, if all the bidders are well informed, the winner is likely to have overvalued the prize - and to come to regret the decision, suffering the winner's curse. But sometimes the highest assessment of value is most nearly correct, and sometimes the object is worth more to the winning bidder than to others.

Second-guessing about the wisdom of the Guidant purchase began well before April 21, 2006, when the deal was consummated. Guidant's cardiovascular devices could be lifesaving. But a stream of news about product de- fects alarmed patients, physicians, and regulators. There were warnings that two models of Guidant's implantable cardioverter-defibrillators could short-circuit and had caused two deaths; some pacemaker models failed to fire appropriately; and defects in coronary stent-delivery systems prevented the angioplasty balloon from deflating, which could lead to emergency bypass surgery or death. The damage to Guidant's reputation was accompanied by drops in its market share and the value of its stock. Opponents of the acquisition noted that the $\$ 27$ billion bid represented 80 times Guidant's earnings - a ratio that could be justified only by the expectation of explosive growth.

There is a broad consensus that the device industry, like the drug industry, will grow as baby boomers age. Some diagnostic devices, such as magnetic resonance 
imaging and computed tomographic scanners, have revolutionized the practice of medicine. Therapeutic devices also offer unique benefits. Electrical stimulators are used to treat refractory pain and several neurologic diseases. Drug-eluting stents have become a mainstay of the treatment of coronary artery disease, and implantable defibrillators reduce mortality among patients at high risk for sudden death from cardiac causes. The success of these innovations demonstrates that device companies that develop new, effective products offer the prospect of better treatment for patients and higher returns for investors.

But not all companies are equally well positioned to benefit from the anticipated increase in sales of medical devices. Large device companies, like large pharmaceutical firms, have had spotty records in developing new products internally, especially when venturing away from their traditional areas of strength. So they fill their product pipelines by purchasing small companies, just as large pharmaceutical companies have grown through acquisitions, mergers, and joint ventures with small biotechnology companies.

The focus and nimbleness that have helped small companies succeed at invention and early development often prove to be liabilities at later stages. Large companies have the resources to shepherd products through approval by the Food and Drug Administration (FDA) and to market them effectively. Furthermore, with multiple products in their portfolios, they can more easily bear the risk that some products will fail. In the past, FDA approval has been a minor obstacle for many types of devices, for which the FDA requires documentation only that a new product is substantially equivalent to one already marketed. Even for genuinely novel devices, efficacy standards have not been as consistently rigorous as for drugs. But payers, who increasingly demand well-designed and wellconducted studies to demonstrate effectiveness before they will provide reimbursement for a new device, may not be satisfied by the evidence used to obtain FDA approval.

For many small companies, the expense of sponsoring or conducting high-quality clinical trials is an insuperable barrier, and few have the experience to market their products effectively. Large companies can finance trials that are large enough to demonstrate efficacy, and they have broad marketing capabilities. By deterring small firms from entering the market with products that are similar or superior to their own, large companies protect their market share - hence the growing domination of the device industry by a small number of companies.

Before the Guidant acquisition, Boston Scientific was among the top three firms manufacturing only medical devices, and it had about $\$ 1.6$ billion in annual sales. But it was heavily dependent on drug-eluting stents for its revenues and near-term growth, and it could not expect to have only one major competitor for very long. Furthermore, it was vulnerable to the displacement of its technologies by newer ones, just as drug-eluting stents have replaced bare-metal stents, and both of these percutaneous interventions have reversed the growth in coronary-artery bypass surgery.

The purchase of Guidant made it possible for Boston Scientific to expand its device offerings into new areas, such as cardiac-rhythm management, mitigating the risk that a loss of market share in any one area would threaten its status as a top device firm. Johnson \& Johnson, by contrast, is a diversified company that did not face the same near-term risks as Boston Scientific, and so it is not surprising that it would decide that alternative growth strategies were more attractive than purchasing Guidant at the price Boston Scientific was offering. Thus, it is plausible that the decisions made by Boston Scientific and Johnson \& Johnson were in the best interests of each company.

Consolidation in the medicaldevice industry, like consolidation in the pharmaceutical industry, has multiple and sometimes unpredictable effects. Mergers and acquisitions are motivated in part by the belief that scale brings reductions in the cost of production and increases in the prices that products command. The resulting profitability may promote innovation, to the extent that profitable companies are more likely than unprofitable companies to invest in research and development. Although novel devices can offer tremendous benefits, industry consolidation is not an unmixed blessing for patients or their physicians. Diminished competition usually means higher prices - and possibly limited treatment options. At least in the short term, increased device-industry consolidation may depress innovation by small companies, which may be deterred by the prospect of competition with large manufacturers. Moreover, consolidation also means that there will be fewer 
large device manufacturers seeking to acquire technology from innovative entrepreneurial firms, and large companies will exercise their greater power as purchasers by paying less to acquire small firms or to license their technology. As one venture capitalist told me, investors will be less willing to put money into device start-ups as the potential return on their investment shrinks.

Distinctions between the market for drugs and the market for devices are becoming less important, as device regulation becomes more uniform and payers demand more rigorous evidence of efficacy. With the implementation of the Medicare prescription-drug coverage under Part D, pharmaceutical companies will turn to Medicare for a large share of their revenue, much as the device industry has done for years, since devices, unlike drugs, were never categorically excluded from Medicare coverage. Perhaps it is inevitable that the device and drug industries will grow to resemble each other even more closely in the coming years, with a small number of very large companies offering a broad array of products, whereas early research will be concentrated in small companies that seek either to license their products or be acquired by large companies.

To generate the revenues needed to justify the purchase of Guidant, Boston Scientific will need to charge high prices for its devices. That will not be easy.
Medicare's fiscal crisis and the increasingly precarious state of private health insurance will bring ever-closer scrutiny of expensive medical care. If the strategy of growth by acquisition permits the device industry to turn scientific advances into effective treatments for patients, it will ultimately succeed in the marketplace. But if this strategy brings about high prices without corresponding benefits, for patients as well as manufacturers, the price of growth will surely have been too high.

Dr. Garber is a staff physician at the Veterans Affairs Palo Alto Health Care System, Palo Alto, Calif., where he is also associate director of the Center for Health Care Evaluation; and he is a professor of medicine, economics, and health research and policy and director of the Center for Health Policy at Stanford University, Stanford, Calif.

\section{The Silent Epidemic - The Health Effects of Illiteracy}

Erin N. Marcus, M.D., M.P.H.

Te came in for a "tune-up." 1 He was 64 years old, with a "history of noncompliance," according to the resident, and he hadn't taken his diabetes or cardiac medications for weeks. We weren't quite sure why. He was alert, he appeared to be intelligent and interested in getting well, and he was able to get his prescriptions filled at a reduced cost. Before he went home, we explained why he needed to take his medicines and reviewed the frequency and doses with him several times. He told us he would follow up with his doctor (though he couldn't remember the doctor's name or telephone number) and left the hospital with a handwritten discharge summary.

Five months later, he appeared at the community clinic. He said he was taking his medications, but he wasn't sure of their names or how often he took them. A medical student and I reviewed the regimen again. The student typed up simple instructions in big letters for him to follow, as well as a list of dates and times at which he should record his blood sugar levels. We asked him to come back in two weeks.

When he returned, the student saw him first - and made a diagnosis that no one else had considered: illiteracy. The clue lay in the jumbled mess of his glucose log. Many of the sugar values were written next to future dates. We quietly asked him to read his list of medications aloud. Haltingly, he told us he couldn't do it. Born in the rural South, he had left school in the second grade. He lived alone. He had been able to support himself as a gasstation attendant and handyman, but he had never learned to read.

We were stunned. We had tried to avoid jargon and to use simple language in explaining our instructions, and he had seemed to understand everything we had told him. He had seen scores of doctors, nurses, and social workers over the years without anyone's guessing he had a reading problem.

Although we had been blind to his illiteracy, our patient's problem is not uncommon. The National Assessment of Adult Literacy (NAAL), a large survey conducted by the National Center for Edu- 